Meta

Journal des traducteurs

Translators' Journal

\title{
Experience and Emotion in Empirical Translation Research with Think-Aloud and Retrospection
}

\section{Gyde Hansen}

Volume 50, numéro 2, avril 2005

Processus et cheminements en traduction et interprétation Processes and Pathways in Translation and Interpretation

URI : https://id.erudit.org/iderudit/010997ar

DOI : https://doi.org/10.7202/010997ar

Aller au sommaire du numéro

Éditeur(s)

Les Presses de l'Université de Montréal

ISSN

0026-0452 (imprimé)

1492-1421 (numérique)

Découvrir la revue

Citer cet article

Hansen, G. (2005). Experience and Emotion in Empirical Translation Research with Think-Aloud and Retrospection. Meta, 50(2), 511-521.

https://doi.org/10.7202/010997ar

\section{Résumé de l'article}

Deux questions importantes se posent sans cesse dans la recherche empirique orientée processus sur la traduction : 1 . Une verbalisation se déroulant en même temps que la traduction, par exemple dans les protocoles de verbalisation à voix haute (TAP), influe-t-elle sur le processus de traduction sous-jacent ? 2. Qu'apprend-on réellement par le biais de méthodes introspectives telles que les TAP et la rétrospection ? Sur la base d'idées développées dans la psychologie moderne et dans la recherche sur le cerveau, on affirme ici que la verbalisation à voix haute doit affecter le processus de traduction. Par ailleurs, on affirme qu'elle produit non seulement des pensées spontanées et non modifiées relatives à la tâche en cours, mais aussi des verbalisations de souvenirs, de réflexions, de justifications, d'explications, d'émotions et d'expériences. 


\title{
Experience and Emotion in Empirical Translation Research with Think-Aloud and Retrospection
}

\author{
GYDE HANSEN \\ Copenhagen Business School, Copenhagen, Denmark \\ gh.first@cbs.dk
}

\begin{abstract}
RÉSUMÉ
Deux questions importantes se posent sans cesse dans la recherche empirique orientée processus sur la traduction: 1. Une verbalisation se déroulant en même temps que la traduction, par exemple dans les protocoles de verbalisation à voix haute (TAP), influe-telle sur le processus de traduction sous-jacent? 2. Qu'apprend-on réellement par le biais de méthodes introspectives telles que les TAP et la rétrospection? Sur la base d'idées développées dans la psychologie moderne et dans la recherche sur le cerveau, on affirme ici que la verbalisation à voix haute doit affecter le processus de traduction. Par ailleurs, on affirme qu'elle produit non seulement des pensées spontanées et non modifiées relatives à la tâche en cours, mais aussi des verbalisations de souvenirs, de réflexions, de justifications, d'explications, d'émotions et d'expériences.
\end{abstract}

\section{ABSTRACT}

In empirical process-oriented translation research with different kinds of introspection, two important questions are raised repeatedly: 1. Does concurrent verbalization, like Think-aloud, have an influence on the translation process and 2. What do we actually learn from introspective methods like think-aloud and retrospection? Based on ideas from modern psychology and brain research, it is argued that think-aloud must have an impact on the translation process. Furthermore, it is suggested that it is not only spontaneous, unmodified thoughts about the actual task that are verbalized, but also memories, reflections, justifications, explanations, emotions and experiences.

\section{MOTS CLÉS/KEYWORDS}

empirical translation research, cognitive processes, decision processes, introspection, brain research, divided attention

\section{Introduction}

Since about 1986, various methods of introspection have been used in empirical translation research, primarily thinking aloud or think-aloud (TA). Jääskeläinen (2002) presents an overview of the use of TA as an empirical method for investigating translation processes. Another introspective method, retrospection, has been used, though less frequently: in research on interpreting, for example, by Kalina (1998) and Ivanova (2002), and in translation research by Hansen (1999), Alves (2003) and Gile (2004).

The following fundamental questions in relation to the choice and application of introspection methods are raised repeatedly:

1. Does TA have an impact on translator's thoughts during the translation process and thereby on the translation product?

2. What is it we actually discover from using methods of introspection?

Meta, L, 2, 2005 
Empirical studies with TA are generally based on the ideas of Ericsson \& Simon (1993: xxii), who say that: "Think-aloud and retrospective reports do not influence the sequence of thoughts. Think-aloud tends to increase the solution time due to the time required for the verbalization."

Toury (1991: 60) has already asked the first of my questions concerning the impact of TA on the translation process. He concluded that simultaneous verbalization must have an influence on the written translation because of the "possible interference of two modes of translation." Gile (1998: 75) pointed out that "The numerous TAP (think-aloud-protocol) studies performed on translators over the past few years also entail a strong possibility of interaction between the research process and the translation process under study."

Whether TA is an appropriate method for obtaining insight into translation processes has often been questioned, and many of these discussions result in the identification of some limitations of the method, for example, that it gives a certain amount of cognitive overload. In many of the studies about TA, however, the usefulness of the method is emphasized, for example by Jääskeläinen (1999: 61), Jensen (2000: 77), Alves (2003: 11). Jakobsen (2003: 93), who investigated the effects of think-aloud on translation speed, revision and segmentation, states that TA has a delaying effect on the translation process and it also has an effect on segmentation, but he concludes nevertheless: "Though this forces us to review assumptions about the think-aloud procedure for translation research purposes, it in no way invalidates the think-aloud method."

In psychology, neurobiology and brain research, conscious and automatic processing, competing mechanisms and divided attention, i.e. whether subjects are able to perform two tasks simultaneously, if both require attention, has been examined by, for example, Hoffstädter (1957), Allport et al. (1972), Shiffrin \& Schneider (1977), Schneider et al. (1994), Raichle et al. (1994), Passingham (1996). In research on interpreting, capacity limits and the question of whether or how well we can perform several tasks simultaneously has been investigated (Strolz 1994, Gile 1999).

Three factors have been identified as being responsible for allowing or not allowing two tasks to be carried out at once. Allport (1972), Eysenck (1993: 51) and Gade (1997: 205) mention that the ability to do two things simultaneously depends on a) the difficulty of the tasks, b) practice, and c) task similarity. Eysenck (1993: 55) says: "As a rule of thumb, two similar, highly practised, and simple tasks can typically be performed well together, whereas two similar, novel and complex tasks cannot." Schneider et al. (1994: 178) have used PET (positron emissions tomography) to investigate brain activity while carrying out on the one hand different, well-learned tasks and on the other hand novel, unpractised tasks. Their results show that automatic processing and controlled processing occur in different areas of the brain. The controlled processing of tasks that involve attention activates the anterior cortical structures, whereas automatic processing is connected to posterior regions. Raichle et al. (1994: 24) also tested the effect of novel and practised tasks (also using PET) and made the observation that the execution of different tasks, demanding different degrees of attention, can be traced to two anterior areas of the brain. These areas showed a great deal of activity during unpractised tasks and less activity when automatic or already practised tasks were carried out. Passingham (1996: 1473) also investigated (using PET) the ability of subjects to perform two tasks simultaneously, when 
both require attention. The results demonstrated that two unpractised tasks cannot be carried out simultaneously without interference, because they both activate the same two areas of the frontal lobe.

\section{Divided attention}

What do these results mean for TA during the translation process? One can conclude that, in translation processes, it is only possible to verbalize, if either translating or verbalizing or, for that matter, both of these tasks do not require attention. But this can easily be the case, when it becomes difficult to verbalize due to factors outside or independent of the task at hand. Translators can have difficulties in carrying out one of the tasks or both of them. Some examples:

There are translators who have had a speech defect, as for example stammering. This does not mean that they are not able to translate. In fact, their translation process is interesting, because they are usually very conscious of every step of their process. Sometimes problems of this kind can be discovered in pilot experiments. Investigations of the translation processes of subjects with this problem showed that they could translate but not verbalize simultaneously with the translation.

Bilingual translators can find that they cannot keep the two languages apart, especially not under stress. In my experiments, the translation process of a bilingual translator showed that she was unable to verbalize while translating, because she immediately faced the problem of code-mixing. She was neither able to translate nor to verbalize and she refused to train verbalizing, because it made her feel very uneasy.

Both conditions, speech defects and code-mixing, made subjects suffer from the fact that they could not coordinate the two tasks. Eysenck (1993: 55) mentions that subjects in such cases tend to have new kinds of coordination problems: "having to perform two tasks together rather than separately frequently produces entirely new problems of co-ordination."

It is obvious that TA cannot be used under such conditions as too much of the translator's attention/concentration is taken away from the translation task.

Another important consideration in the usefulness of TA for investigating translation processes is the direction of translation, i.e. whether it is from the foreign language into the mother tongue or vice versa. Translation into the foreign language is necessary in small countries like Denmark. When translating into the foreign language, verbalization, which normally takes place using the mother tongue, can have an impact on the target text, because it may promote interferences of the kind mentioned by Toury (1995: 235).

Introspective data have frequently been criticized because of their incompleteness. Cognitive processes are often subconscious, automatic processes and therefore not available to verbal reporting (Hönig 1988: 13, Kiraly 1995: 41, and Kussmaul 1998: 50). Many processes, especially processes of trained and experienced translators, are carried out automatically. Another problem is that subjects stop verbalizing as soon as they have translation problems and feel cognitively overloaded.

Under all these conditions TA may not be the most useful method for investigating the translation process, either because having to verbalize can have a disturbing effect on translating - or because translators don't verbalize.

But what would happen in an ideal case, in an ideal situation for using TA? 


\section{The ideal case}

Let us try to imagine an ideal situation, where translators

- do not have any individual problems or negative experiences, which could make verbalization difficult for them

- $\quad$ are not bilingual

- translate into their mother tongue

- $\quad$ are not cognitively stressed by the situation or by the translation task

- $\quad$ have practised TA

- translate, at least partially, consciously

- have something to comment on, during their process of translation.

Would TA have an impact on their thoughts during their working process and on their translation product? Even without doing any experiments, the answer can only be "Yes." But why is that?

\section{Experience, emotion and decision processes}

An answer could already be found with Vygotsky (1956/1974: 353), who states that the structure of language is by no means a reflection of the structure of thoughts. Thoughts that are verbalized are restructured and changed, and language is not merely an expression of a finished thought. The verbalization of a thought must necessarily have an effect on the following thoughts in the process.

Furthermore, recent research in modern psychology and neurobiology, into experience and emotion in decision processes, provides us with some important ideas about cognitive processes which may be interesting in this connection. According to Bruun (2001: 289), decision processes are not only influenced by individual biological conditions but also by cognitive and emotional experiences.

Ericsson \& Simon (1993: 16, 79) have described three different levels of verbalization, "direct or Level 1 verbalization," "encoded or Level 2 verbalization" and "Level 3 verbalization." Level 1 verbalization is the direct vocalization of information in the form "in which it was heeded." In Level 2 and Level 3 verbalization mediating processes occur. Level 2 verbalization involves description, explication and encoding of the thought content. Level 3 verbalization requires explanation of thoughts, ideas and motives in relation to earlier thoughts and information, and also additional interpretative processes.

Ericsson \& Simon claim that the best results are obtained using Level 1 verbalization, which is the concurrent verbal report during the process. They also claim that these direct reports are the "closest reflection of cognitive processes" and, further, they argue that the cognitive processes are not influenced by this kind of verbalization. They state that (1993: 30) "The concurrent report reveals the sequence of information heeded by the subject without altering the cognitive process, while other kinds of verbal reports may change these processes." In most projects with TA, the intention is to obtain such unmodified thoughts, for example Jääskeläinen (2002: 108), who says "The aim is to elicit a spontaneous, unedited, undirected, stream-ofconsciousness type of account from the subject." 


\section{Decisions}

Ericsson \& Simon add (1993: 221f): "Since only one thought can be verbalized at a time, we need a mechanism that determines which one. In addition, we want to specify how non-verbal thoughts are translated into verbal form." They also tell us how the thoughts for verbalization are chosen, "we require that thoughts are selected for verbalization as they are heeded." According to Hoffstätter (1957: 67), however, the choice of a heeded phenomenon always implicitly requires a decision as to what other phenomena are not mentioned.

\section{Experience and emotion}

Ericsson \& Simon also say (1993: 223): "We will also exclude feelings from the thoughts we will consider." The question is, whether it is possible to exclude feelings.

Ericsson \& Simon (1993: 136) also take a stand on the impact of experience or "prior knowledge," i.e. individual knowledge stored in the memory, on verbal reports. They admit that it can be difficult to exclude prior experience, but they are convinced that it is possible: "In cases where we can rule out reproductive or recognition based cognitive processes, we can make strong predictions that any information that is recalled must have been heeded in the experimental situation."

Ericsson \& Simon obviously adhere to a concept of cognitive processes where the relevant thoughts can be selected for verbalization without any influence from other thoughts, and they believe that those verbalized thoughts can be separated from former experience and emotions.

Brain research by, for example, Damasio (1994 and 2003) indicates that the assumption that emotions and reason do not mix might be an "error." He is convinced that it is impossible to separate reason from experience and emotion, and that experience and emotion never can be removed from thoughts. Damasio (1994: 136ff) introduces the notion of innate and acquired dispositional representations or dispositional neural patterns, which are activated the moment we meet a person or confront a situation. These dispositional representations are a myriad of conscious, deliberate considerations about persons or situations, verbal and non-verbal images, which include innumerable aspects and traits, such as reflections and cognitive assessments of incidents to which people react unconsciously. All these images are stored as a collection of separate topographically organized representations that embody knowledge about the usual connection between special types of situations and that carry with them certain emotional responses, and these are stored as unique individual experiences. Through these representations, reactions in the prefrontal cortex are recalled, and the autonomous nervous system reacts in such a way that the experiences, which are normally connected with that kind of situation, are recollected. Such reactions are unconsciously, automatically and involuntarily signalled to the amygdala, and the anterior part of Gyrus cinguli. Coordinated reactions and changes are activated that have an emotional influence on the body, and the resultant emotional condition has, in turn, an important impact on the kind and efficiency of cognitive processes.

In other words, experiences we have had earlier in our lives are stored as dispositional patterns with an emotional content. In novel situations with new experiences, 
these dispositional patterns automatically evoke associations and images through the reactions of neurons in the brain.

When applied to the situation of a translation process, this means that in every situation - be it in connection with a problem that has to be solved or with a decision that has to be taken, or just in connection with some themes or words - a myriad of impulses in the form of images, experiences, associations and emotions immediately and inevitably emerge and influence the process. It also means that if the translator tries to verbalize, only a minimum of all these components of thought can be caught. But perhaps that does not matter, especially not, if the general attitude is as Kiraly (1995: 41) describes it, that most of the supporters of introspective methods claim that "even if verbal reports are necessarily incomplete and do not reveal everything, what they do reveal is important."

During the act of translation and verbalizing, images, emotions and earlier experiences are unconsciously and uncontrollably activated, and these, in turn, have an impact on the actual decisions. All processes influence each other. It seems to be impossible to investigate the intensity of influences from earlier experiences, emotions, conclusions, because, as Bohr (1957: 20) says about analyses of psychological issues: the content of consciousness changes as soon as attention is paid to special traits of it.

Considering the complexity of these processes, which in this article are described in an extremely simplified way, it seems a bit strange to talk about "concurrent" verbalization, because the neural operations of the human mind are carried out at an incredible speed. According to Damasio (1994: 259) "The time scale for the firing (of neurons) is extremely small, on the order of tens of milliseconds - which means that within one second in the life of our minds, the brain produces millions of firing patterns over a large variety of circuits distributed over various brain regions." This means that TA, where thoughts have to be chosen for verbalization, always is retrospective. Verbalizing is a linear activity, because the complex, heeded non-verbal thoughts, which originally are not linear, have to be encoded into verbal form and are, in this process, given a linear structure.

Because of the subtle complexity and the speed of mental processes, verbalization always constitutes a choice from a myriad of thoughts and impulses, which could just as well have been mentioned. Thus, during the translation process, the translator not only takes decisions as to how to translate, but at the same time, decides what to mention and what not to mention - and this happens in accordance with his/her former experience and emotions. As Damasio (1994: 260) says, "Much of the brain's circuitry, at any given moment of adult life, is individual and unique, truly reflective of that particular organism's history and circumstances."

As all the neural processes are interwoven, the answer to the first question - if TA can influence cognitive processes and also the translation product - can only be "Yes." At the same time, the second question can be answered.

The verbal report of a subject comprises only a fraction of all the thoughts during a process, and only those that the subject can single out and encode into verbal form. What thoughts are chosen for verbalization again depends on many aspects mostly, perhaps, on whether the subject has the necessary concepts and is able to talk about a problem. It may also depend on the subject's experiences, conditions in the experimental situation, or just on coincidence. 
Observers are normally not very interested in reflections, justifications and similar data (Ericsson \& Simon 1993: xiv, Ivanova 2000: 33, Jääskeläinen 2000: 108). Maybe the subject may even consciously attempt to omit reflections, explanations, descriptions, justifications, rationalizations and conclusions. Even this process of "having to leave out some kinds of thoughts" must have an impact on the verbal reports.

Not all Ericsson \& Simon's ideas have been adopted without criticism. Bernardini (2001) presents a review of the breakthroughs, as well as the limitations of TA in Translation Studies, and she points out the "necessity to take issues of experimental, theoretical and environmental validity more seriously." Jääskeläinen (2000: 80ff) illustrates some of the methodological problems involved in TAP studies on translating and she concludes "the potential effects of thinking aloud merit systematic investigation." Her proposal is that "we need a thorough methodological investigation specifically designed to determine the effects of verbalizing on the translation product(s)." This is a praiseworthy endeavour, but considering the above described hypotheses and facts from researchers working with neuronal operations, it is doubtful whether a more strict methodological investigation could render any answer to the crucial question of the influences of verbal reports on the thoughts during the translation process.

\section{Reminders}

As already mentioned, a common criticism has been that findings from TA are incomplete, because not all aspects of the mental processes are revealed and, further, because TA only seems to give access to conscious processes. Many translation processes, especially those of professional translators, are subconscious processes, i.e. they are carried out automatically. It has also been observed that subjects tend to stop talking in situations of high cognitive load (Jääskeläinen 1999: 101).

To enhance the production of TA, Ericsson \& Simon (1993: 83/256) propose the use of prompts or reminders to make the subject speak when he/she keeps silent. They propose that after pauses of about 15 seconds to one minute, the experimenter uses expressions like "keep talking" or "what are you thinking about?" Their opinion is that "Reminders to verbalize of the "keep talking" variety should have a very small, if any, effect on the subject's processing." Krings (1987: 173) and Jääskeläinen (1999: 101), however, point out, that minimal intervention on the part of the experimenter improves the ecological validity of the study.

In nearly all studies with TA, during the experiments, researchers try to eliminate social interaction between subject and experimenter as far as possible, because if the two interact, the subject will try to adapt the verbal report to social norms and this could distort the actual mental data. Ericsson \& Simon (1993: xiv) say "social verbalizations may be quite different from the sequences of thoughts generated by subjects themselves while solving problems, performing actions, and making evaluations and decisions." The experimenter should at best be present during the TA experiments, but he or she should remain invisible. The question is then how this can be achieved and how can any effect on the process from the reminders be avoided? Every time subjects are asked to continue talking, they are inevitably also reminded of the fact that they are participating in an experiment and that there is a researcher present 
who is interested in gaining some results. In short, the subject is made aware that it is a social situation of some kind in which they are participating. Such reminders must act as a thought-provoking impulse and their impact on the translation process cannot be evaluated and by no means controlled.

It does not make much sense either that the social factor should be perceived as problematic during the experiments, when after the experiments with TA, it is the experimenter who has to interpret the verbal reports, as Jääskeläinen (2002: 108) proposes:

The resulting data are messy, but it is the researcher's task to make sense of the mess; the translating subjects are not expected to analyse their performance or justify their actions, i.e. thinking aloud as a research tool is not, strictly speaking, a 'mode of reflection.'

On the one hand, during the experiments, the researcher tries his/her utmost to avoid social interaction because he/she is interested in "clean data," i.e. not recalled prior knowledge and/or reflections, explanations, justifications and former experiences. On the other hand, after the experiments, it is the researcher who "makes sense of the mess." What prior knowledge, experiences, emotions, conclusions, expectations and interests does the researcher have? Doesn't this procedure open the floodgates for all kinds of subjective interpretation, especially if there is no clarifying dialogue of any kind with the subject after the experiments?

\section{Retrieval cues: between memory and reflection}

In translation research, retrospection has until now been regarded as a less reliable and error-prone method. Retrospection takes place after the process and subjects easily forget what they have done and tend to distort their observations (Krings 1986: 68). They also infer previously acquired knowledge or explanations. According to Baddeley's (1996) division of the memory into short-term memory, working memory and long-term memory, the possibility to catch spontaneous thoughts is only present during a performance, i.e. when the subject verbalizes concurrently, or if the task is very short - immediately after the task is completed. In these cases, information will still be available in the short-term memory.

As translation processes consist of many simultaneous thought processes, after the task it can be difficult to recall distinct thought episodes. Cohen \& Hosenfeld (1981: 285) distinguish between "immediate retrospection," which has to take place immediately after a task that in itself may not last more than 30 seconds. If the task takes more time, or retrospection starts later, they talk about "delayed retrospection." According to Ericsson \& Simon (1993: xvi/19), the ideal case is where "the retrospective report is given by the subject immediately after the task is completed while much information is still in the STM and can be directly reported or used as retrieval cues." They say that immediate retrospection, only 5-10 seconds after a short task (which also only takes some seconds), would provide even more complete reports than concurrent verbal reports.

Delayed retrospection can take place at any time after the task, but the time interval between the completion of the task and the initiation of retrospection is important, because the risk of forgetting, distorting and incomplete data increases proportionally to the length of the interval between the task and the retrospective report. 
Memory, recognition and retrieval are the most important aspects of retrospection. Ericsson \& Simon (1993: 117) propose that recognition is easiest using "retrieval cues" and that "recall is most likely to be successful if the cueing stimulus is encoded in the same way at recall as it was at the original presentation."

Ivanova (2000: 33) followed this suggestion. In her project exploring aspects of discourse processing in Simultaneous Interpreting, she realized during a pilot study that the most effective cue would be the presentation of the original stimuli in form of the transcript of the SL text. This realization is in accordance with Damasio (1994: 105) who states that the trigger for recall is the reconstruction of a special pattern by activation of "dispositional representations elsewhere in the brain, as in the association cortex."

One central issue in retrospection is the act of "recalling." It has often been mentioned that a few spontaneous, unaltered memories (the good data) tend to be mixed up with inferred justifications, explanations, emotions, prior knowledge and reflections about what the subjects may have thought or done during the process (the bad data), and that keeping them apart can be difficult. Ivanova assumes that with her method she can ensure that the data she gets are recalled from memory and not inferred, and that also negative emotions can be precluded.

Bearing in mind Damasio's (1994: 78) findings concerning the speed of neuronal operations (firing) and the close connections between experience, emotion and reason in the human brain, it is questionable whether spontaneously recalled data about a specific, just finished task can be separated from inferred data or information via reconstruction of previous experiences and emotions. It may not be possible because a precondition for being able to verbalize is that we have concepts, and concepts are adapted over a long period by learning and experience (Vygotsky 1956/ 1974: 215ff). Ericsson \& Simon (1993: 136) also admit that it may be impossible to keep out earlier acquired knowledge held in the memory. They refer to Müller (1911) and say (1993: 19):

A second general problem when retrieving cognitive structures is to separate information that was heeded at the time of a specific episode from information acquired previously or subsequently that is associated with it ...

\section{Conclusion}

In response to the first question posed in this article, it seems clear that TA must have an impact both on the thought processes, on the translation process and on the translation product. All kinds of self-observation, also concurrent thinking aloud, are always retrospective and such retrospection, in turn, affects the following actions in the total process. Individual experiences and emotions are inevitably involved, and these cannot be controlled irrespective of the stringency of the experimental methodology applied.

In answer to the second question - what is it that we learn from introspective methods like think-aloud and retrospection? - it may be concluded that there is much we do not discover, because there is a great deal that is not verbalized or cannot be expressed. What is verbalized is a conglomerate of memories, reflections, justifications, explanations, emotions and experiences, and it seems likely that these cannot be separated from each other, even when we use special reminders or retrieval cues. 
Does this conclusion invalidate introspection methods like think-aloud and retrospection as tools for investigating translation processes?

\section{REFERENCES}

Allport, D. A., Antonis, B. \& P. Reynolds (1972): "On the Division of Attention: A Disproof of the Single Channel Hypothesis," Quarterly Journal of Experimental Psychology 24, p. 225-235.

Alves, F. "A Relevance Theory Approach to the Investigation of Inferential Processes in Translation," in F. Alves (ed.), Triangulating Translation. Amsterdam: Benjamins, p. 3-24.

Baddeley, A. (1995), (1996): Human Memory. Theory and Practice, London: Erlbaum.

Bernardini, S. (2001): "Think-Aloud Protocols in Translation Research. Achievements, Limits, Future Prospects," Target 13: 2, p. 241-263.

Bонr, Niels. (1932)/(1957): “Lys og Liv," In Atomfysik og menneskelig erkendelse I, Copenhagen: J. H. Schultz, p. 11-22.

BruUn, B. (2001): "Børn og unges professionelle voksne," in B. BruUn \& A. KNudsen (eds.), Moderne psykologitemaer. Værløse: Billesø \& Baltzer, p. 278-313.

Cohen A. \& C. Hosenfeld (1981): "Some Uses of Mentalistic Data in Second-Language Research," Language Learning 26, p. 45-66.

Damasio, A. R. (1994): Descartes' Error: Emotion, Reason and the Human Brain, New York: Grosset/Putnam.

Damasio, A. R. (2003): Looking for Spinoza. Joy, Sorrow and the Feeling Brain, New York: Harvest Book Harcourt, Inc.

Ericsson, K. A. \& H. A. Simon (1984), (1993). Protocol Analysis: Verbal Reports as Data, Cambridge, Mass., MIT Press.

Eysenck, M.W. (1993): Principles of Cognitive Psychology, Hove, Erlbaum.

GAde, A. (1997): Hjerneprocesser. Kognition og neurovidenskab, Copenhagen, Frydenlund.

Gile, D. (1998): "Observational Studies and Experimental Studies in the Investigation of Conference Interpreting," Target 10: 1, p. 69-93.

GiLe, D. (1999): “Testing the Effort Model's Tightrope Hypothesis in Simultaneous Interpreting," Hermes, Journal of Linguistics no. 23. p. 153-172.

GiLe, D. (2004): “Integrated Problem and Decision Reporting as a Translator Training Tool," The Journal of Specialised Translation no. 2, p. 2-20.

Hansen, G. (1999): "Das kritische Bewusstsein beim Übersetzen." Copenhagen Studies in Language 24, p. 43-66.

Hofstätter, P. R. 1957. Psychologie. Frankfurt am Main: Fischer.

HöNIG, H. G. (1988). "Wissen Übersetzer eigentlich, was sie tun?." Lebende Sprachen 1. 10-14.

Ivanova, A. (2000): "The Use of Retrospection in Research on Simultaneous Interpreting," in S. Tirkkonen-Condit \& R. JäÄskeläInen (eds.), Tapping and Mapping the Process of Translation and Interpreting, Benjamins: Amsterdam, p. 27-52.

Jаковsen, A. Lyкке (2003): "Effects of Think Aloud on Translation Speed, Revision and Segmentation," in F. Alves (ed.), Triangulating Translation. Amsterdam: Benjamins, p. 69-95.

Jensen, A. (2000), The Effects of Time on Cognitive Processes and Strategies in Translation, Unpublished $\mathrm{PhD}$ thesis, Copenhagen, Copenhagen Business School.

JäÄskeläInen, R. (1999): Tapping the Process: An Explorative Study of the Cognitive and Affective Factors Involved in Translating, Joensuu: University of Joensuu Publications.

JäÄskeläinen, R. (2000): "Focus on Methodology in Think-Aloud Studies," in S. TirkkonenCondit \& R. JÄÄsKelÄInen (eds.), Tapping and Mapping the Process of Translation and Interpreting, Benjamins: Amsterdam, p. 71-82.

JäÄskeläInen, R. (2002): “Think-Aloud Protocol Studies,” Target 14: 1, p. 107-136.

Kalina, S. (1998), Strategische Prozesse beim Dolmetschen, Tübingen: Narr.

Kiraly, D.C. (1995): Pathways to Translation: From Process to Pedagogy, Kent/Ohio: Kent State UP.

Krings, H.P. (1986): Was in den Köpfen von Übersetzern vorgeht, Tübingen: Narr. 
Krings, H.P. (1987): “The Use of Introspective Data in Translation,” in C. FærCh \& G. KASPer (eds.), Introspection in Second Language Learning, Clevedon-Philadelphia: Multilingual Matters, p. 159-176.

Kussmaul, P. (1998): “Die Erforschung von Übersetzungsprozessen: Resultate und Desiderate," Lebende Sprachen Nr.2, p. 49-53.

Mead, P. (2002): "How Consecutive Interpreters Perceive Their Difficulties of Expression," in G. Garzone \& P. Mead \& M. Viezzi (eds.), Perspectives on Interpreting, Forlì, Biblioteca della Scuola Superiore di Lingue Moderne per Interpreti e Traduttori, p. 65-78.

MülleR, G.E. (1911): “Zur Analyse der Gedächtnistätigkeit und des Vorstellungsverlaufes, Teil I," Zeitschrift für Psychologie 5.

Passingham, R.E. (1996): "Attention to Action," Philosophical Transactions of the Royal Society, Series B, Biological Sciences 35, p. 1473-1479.

Raichle, M.E., Fiez, J.A., Videen, T.O., Macleod, A.M., Pardo, J.V., Fox, P.T., and S.E. Petersen (1994): "Practice-Related Changes in Human Brain Functional Anatomy During Nonmotor Learning," Cerebral Cortex 4, p. 8-26.

Schneider, W., Pimm Smith, M. and M. Worden (1994): "Neurobiology of Attention and Automaticity," Current Opinion in Neurobiology 4 p. 177-182.

Shiffrin, R.M. \& W. Schneider (1977): "Controlled and Automatic Human Information Processing: Perceptual Learning, Automatic Attending, and a General Theory," Psychological Review 84, p. 127-190.

Strolz, B. (1994): "Simultankapazität und Übungseffekt," in M. Snell-Hornby, F. Pöchhacker \& K. KaIndL (eds.), Translation Studies. An Interdiscipline, Amsterdam, Benjamins, p. 209-218.

Toury, G. (1991): "Experimentation in Translation Studies: Prospects and Some Pitfalls," in S. TirkKonen-Condit (ed.), Empirical Research on Translation and Intercultural Studies, Tübingen, Narr. 55-66.

Toury, G. (1995): Descriptive Translation Studies and Beyond, Amsterdam, Benjamins.

Vygotsky, L. (1956) / (1977): Tæenkning og sprog, Copenhagen, Reitzel. 